\title{
The Study of European Luxury Brands Use Chinese Zodiac Culture
}

\author{
Wang Siyu, Ning Jun \\ Luxury Brand Design and Management, Beijing Institute of Fashion Technology, Beijing, China
}

\section{Email address:}

artrywsy@126.com (Wang Siyu),biftnj@163.com (Ning Jun)

\section{To cite this article:}

Wang Siyu, Ning Jun. The Study of European Luxury Brands Use Chinese Zodiac Culture. Science Innovation. Vol. 7, No. 4, 2019 , pp. 110-114. doi: 10.11648/j.si.20190704.11

Received: August 18, 2019; Accepted: September 24, 2019; Published: September 27, 2019

\begin{abstract}
Chinese Zodiac culture, as a crucial part of Chinese traditional cultures, is widely adopted by European luxury brands designers under the accelerating waves of globalization. It provides a glorious rising section for the culture connotation of luxury costumes and enhances the communication between eastern-western culture. This reconciliation also benefit for diminishing the potential PR crisis, and it takes into account the aesthetic needs of consumers containing different cultural background simultaneously. This essay aimed at the current atmosphere of European luxury brands which presenting Chinese culture by coalescing Chinese Zodiac portion in their ready-made products, the patterns that how Chinese zodiac elements are applied in these luxuries would be analyzed in this study according to two authentic research methods: relative literature analysis and design comparative approaches, mainly by three different dimensions which are multiple techniques of forming a pattern, various color application methods and appropriate character choosing skills from the aspect of visual communication, based on eight well-known Western fashion luxury brands that produced products emerging Chinese Zodiac elements from 2017 to 2019. Plus, it is important to point out that the essential purpose of approaching research is to provide a valid discussion and summary about the design framework of luxury brands series that relating to Chinese Zodiac elements.
\end{abstract}

Keywords: Luxury Brand, Chinese Zodiac Culture, Visual Communication

\section{欧洲服饰奢侈品牌运用中国生肖文化方式研究}

\author{
王思雨, 宁俊 \\ 北京服装学院奢侈品设计与管理, 北京, 中国
}

\section{邮箱}

artrywsy@126.com（王思雨），biftni@163.com（宁俊）

\begin{abstract}
摘要：中国生肖文化作为中国传统文化的一部分，在全球化的浪潮下广为传播受到欧洲服饰奢侈品牌的青睐，为欧洲 服饰类奢侈品牌的文化内涵增添了新的血液，推动了东西方文化的交流，有利于避免品牌公关危机，兼顾了不同文化 背景消费者的审美需求。本文针对欧洲服饰奢侈品牌运用中国生肖文化设计产品对中国传统文化进行诠释的现象, 采 用文献调查法与比较研究法对2017年至2019年生产中国生肖文化产品的八个欧洲服饰奢侈品牌, 从视觉传达的角度以 图案的造型手法、色彩的运用方式、文字的选择三个维度, 研究欧洲服饰奢侈品运用中国生肖文化的方式。通过研究, 旨在对奢侈品牌的中国生肖系列产品 从其设计规律到对于品牌方的影响进行有益的理论总结与探讨。
\end{abstract}

关键词：奢侈品牌，中国生肖文化，视觉传达 


\section{1. 引言}

随着全球化进程不断推进，东西方文明的不断交融， 中国生肖文化受到欧洲服饰奢侈品牌的青睐。国内外学术 界从消费符号与消费心理学的维度探究奢侈品牌运用中 国文化的现象, 对中国生肖文化商业运用的视觉特征进行 了研究。但并未将中国生肖文化与欧洲服饰类奢侈品牌相 关联。本文选取2017年至2019年期间推出中国生肖文化产 品的部分欧洲服饰类奢侈品品牌从涉及的视觉传达的图 案、色彩、文字三个维度对服饰类奢侈品牌运用中国生肖 文化方式进行分析。探究设计模式及对品牌方产生的影响。

\section{2. 视觉特征分析}

欧洲服饰奢侈品牌的产品设计不仅在维护品牌的美学 与艺术层次, 更是在构建品牌独有的文化财产, 维持自身的 品牌形象, 所设计生产的产品及传达的信息以视觉传达为主 要的途径, 为消费者所感知。设计具有美感、信息的有效传 达均有利于奢侈品牌的产品设计与品牌构建。一件设计作品 一般包括三个维度: 色彩、图形、文字。服饰类奢侈品运用 中国生肖文化的视觉元素可通过以上三个维度进行分析。[1]

\section{1. 图案运用}

通过查阅2017-2019年部分欧洲服饰类奢侈品牌产品 研究分析, 欧洲服饰奢侈品牌运用中国生肖文化所设计的 图案分为以下四个维度 (见表1）：原创图案即奢侈品牌 自主设计以绘制为主要创作手法的图案; 拼贴图案即以拼 贴的手法解构重组形成的图案; 抽象图案即服饰奢侈品牌 对生肖动物的造型与特征以艺术的视角进行抽象概括形 成的图案; 联名图案即服饰类奢侈品牌与知名IP进行合作 在生肖产品中运用联名IP的图案。

\subsection{1. 图案运用种类}

原创图案: 由艺术总监结合生肖形象为服饰奢侈品牌 设计创作独特的生肖图案, 知识产权亦是奢侈品牌宝贵的 资产, 在设计中国生肖文化相关产品时, 选择绘制品牌独 有的生肖图案有助于丰富品牌无形资产。

拼贴图案:运用中国生肖文化时采用拼贴的艺术手 法进行图案设计。路易威登在历年生肖产品中多运用了拼 贴手法进行设计, 多见于皮质钥匙扣、丝巾、箱包中, 而 其经典的Monogram涂层帆布纹样被通过拼贴的形式与中 国生肖文化中的生肖拼贴融合如图1所示。通过元素的对 峙杂糅, 通过物体的互相穿插, 形成虚实与前后的比拟。 [2-4]表现品牌传达的信息。

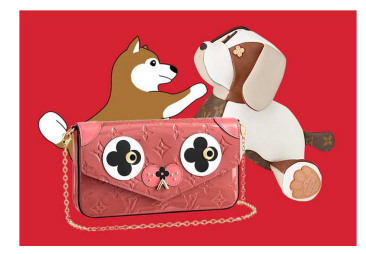

图1 路易威登品牌的拼贴图案。
抽象图案:抽象是具体形象象征体的表现形式, 也是 欧洲服饰奢侈品运用中国生肖文化以图案的形式表达的 一种形式, 相对于将过于具象的图案运用于产品中, 抽 象的生肖具有着高辨识度以及凝练的美感, 具有着强烈的 张力与表现力增强了作品与消费者在审美上的契合 [5]。中 国审美强调气韵讲究形与象相互呼应的重视精神愉悦的 特征, 与抽象的形式不谋而合。

联名图案: 顺应潮流时尚趋势, 吸引更多消费者扩充 流量等原因, 奢侈品牌选择联名策略, 不乏服饰类奢侈品 牌运用联名图案的现象出现。Gucci、Moschino、Longchamp 品牌近年均将了与知名IP跨界联名的图案, 运用到生肖产 品中(如图2)。

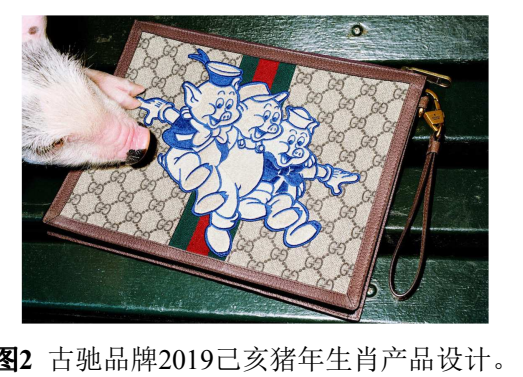

\subsection{2. 图案运用现状分析}

表1 2017-2019年部分欧洲奢侈品牌运用中国生肖文化图案表。

\begin{tabular}{llll}
\hline \multirow{2}{*}{ 品牌 } & 年份 & & \\
\cline { 2 - 4 } & $\mathbf{2 0 1 7}$ & $\mathbf{2 0 1 8}$ & $\mathbf{2 0 1 9}$ \\
\hline 古驰 & 原创图案 & 原创图案 & 联名图案 \\
路易威登 & 拼贴图案 & 拼贴图案 & 拼贴图案 \\
爱马仕 & 抽象图案 & 抽象图案 & 抽象图案 \\
龙骧 & 原创图案 & 联名图案 & 联名图案 \\
莫斯奇诺 & 无 & 联名图案 & 联名图案 \\
迪奥 & 抽象图案 & 抽象图案 & 抽象图案 \\
沛纳海 & 原创图案 & 原创图案 & 原创图案 \\
萧邦 & 原创图案 & 原创图案 & 原创图案 \\
伯爵 & 原创图案 & 原创图案 & 原创图案 \\
\hline
\end{tabular}

通过比较研究法分析可得出表1中欧洲服饰类奢侈品 牌：（1）沛纳海、伯爵、萧邦钟表类 品牌相对于服装类 奢侈品牌更注重中国生肖文化象征在图案中的运用、(2) 奢侈品牌注重绘制品牌独有的生肖图案、（3）品牌DNA 充满活力、开拓年轻市场、品牌历史较短的奢侈品牌, 更 倾向于尝试联名图案。

\section{2. 色彩运用}

服饰奢侈品牌运用中国生肖文化设计的作品均通过 视觉的形式吸引消费者。[6]文字、图形、色彩均可通过视 觉传达的编码形成传递信息的媒介, 图形与色彩密切相关, 色彩的运用与对象之间易形成一种固有关系, 意为在人们 的脑海中形成了先入为主的印象, 某种意象与某种色彩之 间存在一种内在的联系, 即惯用色或是形象色（例如香奈 儿品牌惯用的黑白色, 思考中国龙的意象时多易于联想到 金色）。这是基于人们对意象属性判断的经验, 是经过长 期积累形成的潜意识。[7] 


\subsection{1. 色彩运用种类}

通过查阅2017-2019年部分欧洲服饰类奢侈品牌运用 中国生肖文化所生产的产品文献分析得出色彩运用分为 以下三类

固有色: 以路易威登与古驰品牌为例, 历年推出的生 肖箱包均有出现以品牌经典老花图案是棕色为底色, 古驰 品牌结合品牌代表的红绿相间条纹进行设计如图2所示。 在奢侈品牌运用中国生肖文化设计产品时, 其本质仍是为 品牌服务, 固有色的运用体现奢华尊贵、品质卓越、蕴含 匠心, 品牌固有色的使用有助于体现品牌特征向消费者传 达品牌信息, 材质固有色的使用则有助于产品表达奢侈品 华贵上乘的信息。

生肖代表色: 生肖年年更替故生肖代表色的运用较 固有色与中国代表色多变, 在2018戊戌狗年中奢侈品牌 多运用黑、白、棕黄色等犬类毛发代表色作为设计生肖 形象与图案的色彩。以色彩的方式向消费者点明该年生 肖形象。
中国代表色: 中国代表色多为金色与中国红红色是中 华民族喜闻乐见的颜色，使用中国红与金色易于联想至中 国。运用中国生肖文化时采用中国红通过色彩的层面言简 意赅地表述了与中国的联系。[8]

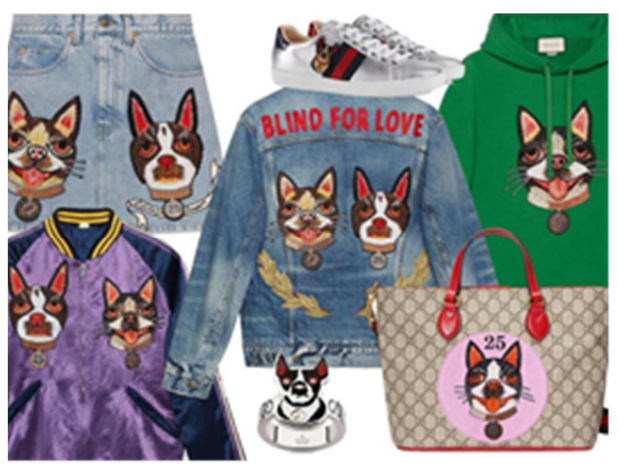

图3 古驰品牌2018戊戌狗年生肖产品设计。

\subsection{2. 色彩运用现状分析}

表2 2017-2019年部分欧洲服饰奢侈品牌运用中国生肖文化色彩表。

\begin{tabular}{|c|c|c|c|}
\hline \multirow{2}{*}{ 品牌 } & \multicolumn{3}{|l|}{ 年份 } \\
\hline & 2017 & 2018 & 2019 \\
\hline 古驰 & 固有色、生肖代表色、中国代表色 & 固有色、生肖代表色 & 固有色、生肖代表色 \\
\hline 路易威登 & 固有色、生肖代表色 & 固有色、生肖代表色 & 固有色、生肖代表色 \\
\hline 爱马仕 & 固有色、生肖代表色 & 生肖代表色 & 生肖代表色 \\
\hline 龙骧 & 中国代表色、生肖代表色 & 生肖代表色 & 生肖代表色 \\
\hline 莫斯奇诺 & 无 & 生肖代表色 & 生肖代表色 \\
\hline & 材质色、生肖代表色、中国代表色 & 材质色、生肖代表色、中国代表色 & 材质色、生肖代表色中国代表色 \\
\hline 沛纳海 & 固有色、生肖代表色 & 固有色、生肖代表色 & 固有色、生肖代表色 \\
\hline 萧邦 & 固有色、生肖代表色 & 固有色、生肖代表色 & 固有色、生肖代表色 \\
\hline 伯爵 & 固有色、生肖代表色 & 固有色、生肖代表色 & 固有色、生肖代表色 \\
\hline
\end{tabular}

通过比较研究法分析得出：2017-2019年以生肖代表 色为主，固有色、生肖代表色、中国传统色多以组合形式 出现但无固定组合搭配（见表2）。奢侈品牌在运用中国 生肖文化设计产品时, 在色彩的维度需要考量品牌自身的 色彩、体现生肖的色彩、体现中国文化的色彩中进行平衡 与取舍。

\section{3. 文字运用}

文字不仅可以传达文字信息，其本身也具有可视觉 识别的特征。奢侈品牌在运用中国生肖文化设计产品时 多采用图像的形式, 而较少运用中国的文字元素。谐音 谐意的现象广泛地出现在世界各国的语言文字之中, 谐 音是指音同或者音近的现象。[9-10]猴谐音“侯”有着加官 进爵的意象，生肖文化中并不是所有的生肖都完全具有 正面积极的寓意, 例如鼠除了机智灵巧之外代表着偷盗、 有着鼠目寸光等成语。相对于视觉图像而言, 若在含有 负面意义的生肖年份中运用该年份的生肖汉字，奢侈品 牌易于出现公关危机的隐患。无论用何种字体书写, 文 字的基本架构无法改变的。图像相对于文字本身具有更 高的灵活性, 大大降低了品牌出现与中国文化相关的公 关危机的可能性。

\section{3. 创作模式}

近年欧洲服饰类奢侈品牌在运用中国生肖文化的产 品设计与创作中以突出生肖动物本身的形象为主, 创作模 式可归为以下三类。

\section{1. 结合中国传统文化}

生肖文化经常与春节文化一同出现, 品牌运用与中 国传统文化相关联的符号结合生肖动物的形象进行创 作。[11]沛纳海品牌将生肖动物与中国传统的剪纸元素 进行结合进行生肖腕表图案的设计, 并且11年延续这一 设计思路。迪奥品牌将中国传统民俗文化中的本命年戴 红绳的习俗将生肖形象与中国传统文化结合设计生肖 珠宝。将当年的生肖形象与中国传统文化结合为设计本 身添加了中国元素, 更加明确地凸显了中国生肖文化的 母题。与中国传统文化结合进行创作是必然蕴含着中国 传统文化内涵与意象, 且这一设计理念被品牌方长期使 用, 偶然地使用中国红色或是剪纸元素并不属于与中国 传统文化结合的范畴。 


\section{2. 结合品牌文化}

品牌文化是品牌经历长时间发展与不断经营中的文 化积淀, 是品牌与消费者共同的利益认知是品牌与传统文 化、企业个性的总和与情感归属。[12]将中国生肖文化创 作与品牌文化结合, 具有代表性的品牌为路易威登品牌。 运用拼贴的手法其经典的Monogram纹样与中国生肖形象 进行结合（如图4）。在丝巾设计中将Monogram纹样打散 结合生肖特征融入设计之中。

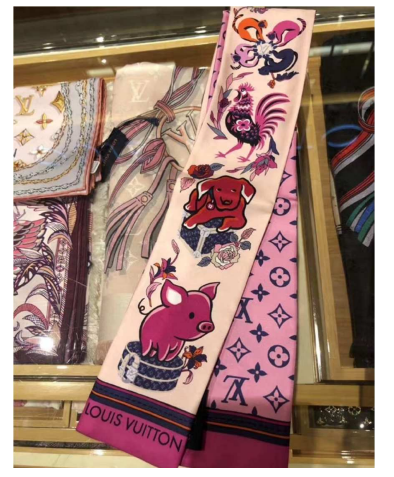

图4 路易威登品牌设计的中国生肖文化产品。

\section{3. 结合联名形象}

中国生肖文化作为中国传统文化的一部分具有一定 的传统性, 但传统是在不断变化与发展中形成的, 一味地 拘泥于传统的形式难以适应当代审美的发展与文化的潮 流。[13]服饰类奢侈品牌中品牌历史较短、品牌DNA充满 活力、近年品牌战略及目标客户群体为年轻市场的奢侈品 品牌选择与卡通IP或者网络意见领袖进行联名。与联名形 象结合在服饰类奢侈品牌设计中国生肖文化产品的过程 中, 由于意见领袖自身具有流量而经典动物IP已是消费者 所接受的动物形象从而降低了品牌方的产品的推广门槛。

\section{4. 影响}

以中国生肖文化作为母题, 通过奢侈品牌的符号以及 生肖动物符号向消费者传达信息,有助于避免文化冲突与 奢侈品牌公关危机的出现。

\section{1. 减少审美冲突}

时代的发展与变化, 不同的时代背景以及民族文化有 着各自的差异，但随着全球化进程的不断推进与信息媒体 传播的即时性，经济、信息、文化趋于全球化。传统审美 与文化呈现明显的地域化特征, 而当代的流行文化具有广 泛传播与全球化的特点, 即对于审美的认知与选择具有共 通性。[14]当下以中国生肖文化为母题所创作的产品属于 当代文化的范畴, 是蕴含着传统文化与当代流行文化的设 计。与中国传统文化结合、与品牌文化结合或是选择与联 名形象结合都一定程度上跳脱出东方主义的禁锢, 避免了 审美冲突的产生。

\section{2. 避免品牌公关危机}

前文所述母题与主题的不同在于其是客观的, 所传达 的信息简化，不具有导向性，这赋予消费者自身以自由理 解作品的权力, 稀释了品牌方对于产品传达的信息的责任。 仅是以当年生肖动物形象为主的设计创作, 前文中对于东 方文化的偏见以及曲解都可以从源头上得以一定程度的 避免。难以发生类似杜嘉班纳品牌“起筷吃饭”品牌危机事 件发生。

\section{3. 满足不同文化背景消费者的需求}

服饰奢侈品牌的生肖文化产品不仅面对的是以中国 为主的消费者群体，需要满足不同国家以及文化背景的消 费者的审美需求。[15]受中国文化辐射的日本同样受到中 国生肖文化的影响, 2018戊戌狗年路易威登与伯爵品牌便 选用了日本柴犬作为生肖动物形象。选择了与知名动物IP 进行联名的服饰类奢侈品牌而言, 选择运用IP动物形象不 仅满足了中国消费者对于生肖动物形象的认知, 更是满足 了不同文化背景消费者的认知需求。对于生肖动物形象的 设计不局限于中国传统形象有助于服饰类奢侈品牌吸引 更多的消费者。

\section{5. 结论}

随着全球化进程的不断发展, 中国生肖文化与欧洲服 饰奢侈品牌结合丰富了欧洲奢侈品牌运用中国生肖文化 的视觉形式。探索了中国生肖文化与欧洲服饰奢侈品牌结 合的道路, 是欧洲商业品牌对于中国文化以及中国市场相 结合的探索更是东西文化相互的交流, 有助于中国传统文 化在世界范围的传播与发展。

\section{致谢}

本文为北京市社科基金项目《北京居民服装绿色消费 认知、态度与行为研究》 (18JDGLB029) 与北京市科委 重大项目《服装柔性设计智能智造服务平台研发及应用》 （Z171100005017004）的阶段性成果之一。

\section{参考文献}

[1] 马方春.试论色彩、图形、文字在平面设计中的运用[J].艺术 百家，2011，（z2）;176-178。

[2] 兰新成,陈宏伟.拼贴形式设计方法的深度解读[J].南京艺术 学院学报（美术与设计版）,2015,(6):143-146。

[3] 万千个. 拼贴手法在艺术领域中的运用 [J]. 美术大 观, 2018,(9):54-55。

[4] 林浩晗.招贴设计中的拼贴艺术[J]. 艺海, 2017,(10):116-118。

[5] 李萌.抽象造型语言在当代插画中的应用研究[]].戏剧之 家,2018,(12):109-110。 
[6] 王美慧. 视觉传达设计中的色彩运用 [J]. 数码设计 (下) ,2018,(11):186-187。

[7] 刘燕.视觉传达设计中视觉元素的运用分析 [J]. 包装世 界,2019,(3):28,30。

[8] 胡云青.“中国红”在现代艺术设计中的应用[D].河北:河北工 业大学,2013。

[9] 郑勇.汉语谐音修辞多维研究[D].安徽:安徽大学, 2013。

[10] 刘炜. 略谈汉字"鸡"的谐音语用 [J]. 现代语文（语言研 究 ),2006,(1):38-39.DOI:10.3969/j.issn.1008-8024-C.2006.0 1.019 。
[11] 钟立生,陈丽东,邵逸清.试析生肖文化在中国的影响 [J].知识 经济,2013(20):39-41。

[12] 曹琳.奢侈品品类创新的机制与案例研究 [J]. 经济经 纬,2013,(5):90-94。

[13] 李楠. 传统生肖元素的现代设计表达 [J]. 服饰导 刊,2013,2(04):76-80。

[14] 袁淑芸.消费时代品牌文化中的审美价值一以奢侈品为 例 [J].经济研究导刊,2011(26):273-274+27。

[15] 刘燕.视觉传达设计中视觉元素的运用分析 [J]. 包装世 界,2019,(3):28,30。 